\title{
Journal of Research in Engineering and Applied Sciences \\ A SURVEY ON PROGRESS AND DEVELOPMENT OF INDUCTION MOTORS' INCIPIENT FAULT DETECTION TECHNIQUES DURING LAST THREE DECADES
}

\author{
G. N. Surya ${ }^{1}$, M. S. Ballal ${ }^{2}$, and Z. J. Khan ${ }^{3}$ \\ ${ }^{1,3}$ Rajiv Gandhi College of Engineering Research and Technology, Chandrapur, Maharashtra, India \\ ${ }^{2}$ Visvesvaraya National Institute of Technology, Nagpur, Maharashtra, India
}

Abstract

\{E-mail : ${ }^{2}$ drmsballal@rediffmail.com\}

Enhancement of induction motors efficiency and their life span through various incipient fault detection and diagnostic methods has been the focus of a number of intensive researches carried out during last 33 years since 1980. The tools and techniques employed in those researches vary from use of sensors to steady-state spectral components of the stator quantities. Abnormalities contribute towards accelerated aging and sudden failure. In the absence of critical component's behavior monitoring, the failure risk is always high. Induction motor being the critical component of industrial productivity their upkeep and trouble free operation is of immediate industrial need to minimize the down time costs. Owing to this requirement, a number of on-line and off-line diagnostic tools and techniques have been developed over the period of time. This paper deals in-depth with categorizing the diagnostic tools and techniques chronologically as per their evolution since 1980 onwards. It is shown that distinct techniques have been introduced in the survey with many variations in their implementation. These techniques encompass around 25 (twenty five) formidable methods employed in various researches. It is expected that this manuscript serves as a convenient reference for future work, pinpointing the up-to-date progress and observed limitations in induction motor incipient fault detection and diagnosis tools and techniques.

Keywords: - Current Signature Monitoring; Feature Extraction; Flux Monitoring; Incipient Fault Detection (IFD); Parameter Estimation; Steady-State Spectral Components

\section{Introduction}

Tracking the faults in the stages of their development prior to failure of critical components of the motor drive system is usually an essential part of condition monitoring and health diagnosis of induction motors. Induction motors are widely used in industries, and there is a strong demand for their reliable and safe operation. They are referred as "workhorses" of industry. These electrical machines are frequently exposed to non-ideal or even unfavorable operating conditions. These conditions include overload, insufficient lubrication, frequent motor starts/stops, inadequate cooling, dusty environment, humid atmospheric conditions, high temperature, variations in terminal voltage, fluctuating load etc. Under these conditions, electric motors are subjected to undesirable stresses, which put the motor under risk of faults or failures.

A. Incipient Fault Diagnosis of Induction Motors

Fault diagnosis is defined as the continuous evaluation of the health of the plant and equipment throughout its service life. It is important to be able to detect faults while they are still in the developing stage. This is known as incipient failure detection [1] which provides a safe operating environment. It is becoming increasingly important to use comprehensive monitoring schemes for continuous assessment of the overall condition of electrical machines. By using diagnostic techniques, it is possible to provide adequate warning of imminent failure. In addition, it is also possible to schedule predictive maintenance and reconditioning work. This can result in minimum down time and optimum utilization of electrical machines [2]. Therefore, cost effective diagnosis of electrical machines is critical in improving the reliability, safety, productivity and cost benefits. Incipient fault diagnosis has great significance due to following reasons.

- To reduce the cost of maintenance/replacement

- To predict the equipment failure

- To improve equipment and component reliability

- To optimize the equipment performance 
- To improve the accuracy in failure detection

B. Critical Components and associated faults Stator and rotor windings, insulation, air gap (static, dynamic as well as mixed eccentricity), bearings, rotor bars (in case of squirrel cage motors), end rings, and shaft (misalignment) constitute the critical components of induction motor system. Regardless of causes, stator winding-related failures can be divided into five categories: turn-to-turn, coil-to-coil, lineto-line, line-to-ground, and open circuit faults as shown in fig. 1 . The stator winding inter turn fault, if not attended timely, leads to catastrophic failure of entire motor system.

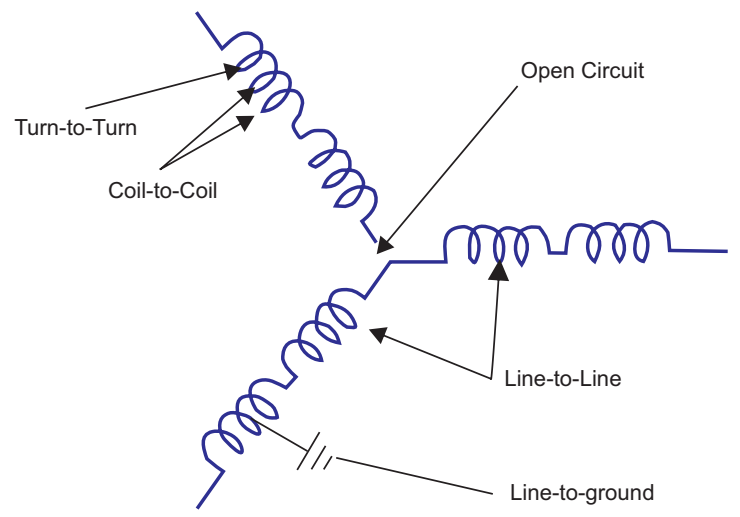

Fig. 1: Stator winding faults in Induction Motors

Vibrations and noise are often observed as a common fault in induction motors. They are produced due to air gap eccentricity. If the rotor is not centre aligned, the geometric centre of the stator bore is not in alignment with rotor's centre of rotation resulting into unbalance of radial forces. It causes a stator-to-rotor touch damaging the stator as well as rotor.

As per the survey on motors conducted by Electric Power Research Institute (EPRI) and as in [3], [4], most faults occur due to bearings and stator winding as detailed below.

- Bearing related faults $-41 \%$

- Stator winding insulation and other related faults $-37 \%$

- Rotor related faults-10\%

- Others faults - $12 \%$

Cracking of rotor bars, melting of end rings and misalignment of shaft are also most frequently observed in induction motors. Defects in brazing process, heavy end rings, and thermal stresses on rotor bars restricting its longitudinal movement in occupied slots are the main reasons of rotor faults.

\subsection{PROBLEM OVERVIEW}

Incipient fault detection tools and techniques are continuously experiencing changes not only in their implementation modes but cost effectiveness as well. Given a large number of methods, it has been thought that a survey of methods implemented so for would be beneficial to researchers and practitioners in incipient fault detection and diagnosis. The number of papers has grown considerably during the last two decades. Thus, the survey encompasses the great majority of papers and techniques presented so for during last three decades on Incipient Fault Detection (IFD). During the process of this study it has been specifically felt that the voluminous IFD literature to review warrants the need for brevity.

In this study 180 (one hundred and eighty) papers published up to the date of submission of this manuscript, related with incipient faults, have been analyzed in-depth. Year wise breakup of these papers included in this review, has been depicted by means of histogram shown in figures 2 . It has not been intended to establish a literal chronology of when various techniques were proposed, since every subsequent method is mostly an extension of previous method differing only in implementation. However, a lot of omissions were done when no substantial difference in detection techniques were observed in one or more papers. We apologize if an important method or substantial improvement was left out unintentionally.

This manuscript steps through a wide variety of methods with a brief discussions and categorization of each. It includes the most recent research work up to September 2013, in the form of futuristic trends of research, in the last phase of literature review. The manuscript concludes with a discussion on the different methods based on their implementation, the minimum tools, and above all simplicity and 


\section{Year-wise Break-up of Incipient Fault Research \\ Studies}

(1980 to September 2013)

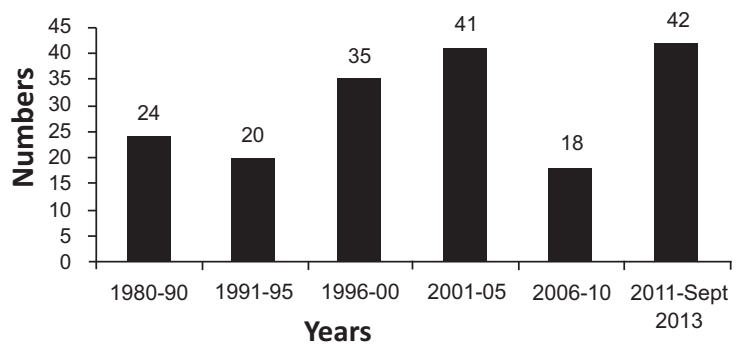

Fig. 2: Year-wise break-up of incipient fault research studies

cost effectiveness of diagnostic system, which is the need of the hour.

\section{PHASES IN DIAGNOSIS PROCESS}

The Basic aim of any diagnosis process is to determine the existence of any deviation in the measurable parameters from their set values corresponding to normal behavior (operation). In case of induction motor diagnosis, the entire process usually consists of four phases: Data acquisition, Feature Extraction, Fault Progression and Trend Analysis, and Decision making.

Usually, in these phases, a lot of monitoring activities are involved. For each type of monitoring, a different tool or technique is employed. In case of incipient fault diagnosis of induction motors, following types of monitoring by means of independent techniques are involved.

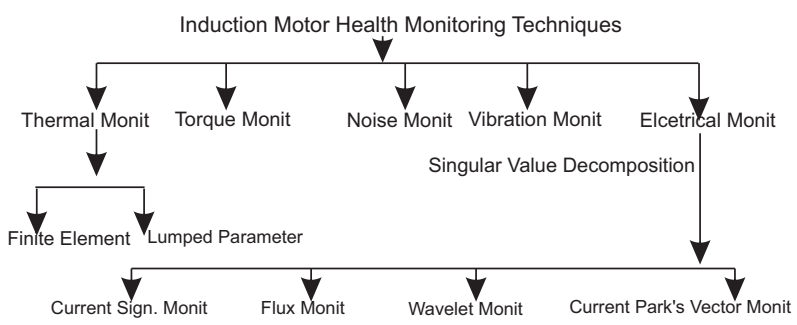

Fig. 3: Different types of condition monitoring techniques

\section{INCIPIENT FAULTS DETECTION AND DIAGNOSIS TECHNIQUES IN EXISTENCE}

The history of fault detection and diagnosis of electrical motors goes back to almost the date of their invention. Manufacturers and users of the motors have been the first ones who have investigated simple protection techniques such as over current, over voltage and ground fault protection schemes. However, the increase in the complexity and the importance of the motor's role has generated a corresponding significant progress in the field of fault detection and diagnosis, with a general aim to avoid accidental and unpredictable shutdown of equipment. The down time of plants lead to financial losses that cannot be recuperated. In addition, repair of such motors is time consuming and has considerable expenses [5]. Owing to the necessity of an effective detection and diagnosis technique, for detection of incipient faults in induction motors, various techniques kept on getting developed over the period of time. It has already been stated that existing voluminous literature related to incipient fault diagnosis and detection to review necessitated the need for brevity, and hence became the standpoint for writing this review with classification of various techniques and the methods suggested so for under those techniques over the period since 1990 up till date. Though many challenges were faced yet consistent efforts were taken during the process of development of those techniques to overcome the limitations and problems faced earlier. For example the fault signature, i.e., the stator current is $50-80-\mathrm{dB}$ smaller than the signals themselves [6]. In such cases, even the manufacturing defects could be treated as fault signals. The other problem faced was due to the fact that no two machines have identical characteristics, even if they were from the same assembly. Following seven techniques used so for in various researches, have been reviewed in this manuscript. Fig. 3 below, depicts the technique wise break of research studies included in this review. 
Technique-wise break-up of incipient Fault

Research Studies

(1980 to September 2013)

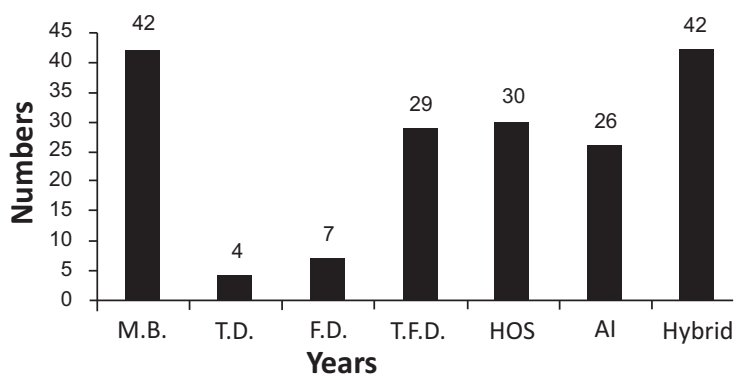

Fig. 4: Technique-wise break-up of incipient fault research studies

\section{A. Model Based Techniques (MB)}

Induction motors can be modeled as three phase models or two phase models. Model based techniques for detection of faults like stator inter-turn shorts, broken rotor bars and bearing faults have been extensively explored during 1980's and 1990's. In [7], [8], three phase model of induction motor for fault detection has been analyzed. Three phase induction motor has three phase symmetrical winding in the stator, displaced by $120^{\circ} \mathrm{N}_{\mathrm{s}}$ with equivalent turns. The rotor winding also contains a three phase winding, displaced by $120^{\circ}$ with $\mathrm{N}_{\mathrm{r}}$ equivalent turns. The three phase axis of the stator and the rotor are separated by the rotor angle $0_{r}$ Subscripts $\mathrm{S}$ and denote $\mathrm{r}$ properties belonging to the stator and the rotor respectively. Multiple quadrature models with significant differences depending on the frame type and application, in the form of a) the arbitrary reference frame, b) the rotor reference frame, and c) the stator reference frame have been used in a number of studies for detection of various faults [9]-[11].

Two phase models also have generally been widely utilized in different applications, and more frequently than three phase models. Especially in the application areas of indirect faults detection, parameters estimation and identification, the two phase models provide a better representation of an induction motor model in a state space formulation [12]-[14]. The voltages equations can be simplified, if the three phase stator and rotor windings are replaced by their equivalent quadrature phase windings [15]. A mathematical model based technique was used in [6] to match the vibration response of the system due to the faults present in the bearing. In the technique proposed in [16], the description of the vibration produced by a single point defect on the inner race of a rolling element bearing under constant radial load was done with the help of a model. The bearing geometry, shaft speed, bearing load distribution were some of the features incorporated by the model suggested. The model helped in comparing the predicted and demodulated vibration spectra. Quantitative evaluation of induction motor broken bars by means of electrical signature analysis was presented in [17].

The model based techniques were extensively used during 1980's and 1990's. They depended upon development of "smart" condition monitoring systems. Their success depended on their accuracy as well as on their ability to discriminate between normal/balanced and abnormal/unbalanced conditions. Hence, the possibility of simulating fault conditions became more attractive and important. In papers [18]-[42] researchers have put in a lot of efforts to predict the performance of induction machines using various modeling/simulation techniques and tools for stator faults. The steady-state and transient state of healthy and faulty machines under different operating conditions like steady-state (no load and on load) and transient state (startup, loading, unloading, and shutting down), have been thoroughly considered. A transient model for an induction motor with stator winding turn faults on a single phase has been derived using reference frame transformation theory. The dynamic equations were presented in statespace form, which is suitable for digital simulation. Experimental results, with correction applied for the effects of inherent asymmetry, have been shown to exhibit the same trend as predicted by the model [43]. The authors in [44] gave a new model of squirrelcage induction motors under stator and rotor 
faults. First, they studied an original model that takes into account the effects of inter turn faults resulting in the shorting of one or more circuits of stator-phase winding. They introduced, thus, additional parameters to explain the fault in the three stator phases. Then, they proposed a new faulty model dedicated to broken rotor bars detection. The corresponding diagnosis procedure based on parameter estimation of the stator and rotor faulty model was proposed. The estimation technique was performed by taking into account prior information available on the safe system operating in nominal conditions. A special three-phase induction machine was designed and constructed in order to simulate true faulty experiments. Experimental test results showed good agreement and demonstrated the possibility of detection and localization of previous failures. Online, stator winding turn fault detection using negative sequence current as a measure of fault severity or to initiate protective action such as circuit breaker trip was successfully employed in [45]. A power decomposition technique (PDT) has been used in [46] to derive positive and negative sequence components of measured voltages and currents to diagnose on line stator faults. A new method using multiple reference frame theory for diagnosis of stator faults in three phase induction motors was presented in [47]. The method proposed can also be suitably extended for diagnosis of other asymmetries such as broken rotor bars and air-gap eccentricities. Stator fault estimation has been carried out using Particle Swarm Optimization technique in [48]. The proposed algorithm monitors the spectral content of stator currents to detect the fault using a complete model of the faulty motor.

\section{B. Time Domain Techniques (TD)}

Time Domain analysis is one of the simplest methods for detecting incipient bearing faults. It can be done either visually or by applying some statistical parameters such as Crest factor, Root Mean Square Value, Kurtosis Value etc. These have a greater value when the machine is under fault compared to the faultless condition. Parameters like crest factor and kurtosis give spikiness of the signal and not the vibration magnitude. Initially, the crest factor and kurtosis increase as the spikiness of the vibration increases, but as the damage increases the vibration becomes random and these values move towards normal values. Thus, the time domain analysis lacks the ability to track the defects in the later stages of the fault. Time domain analysis technique to detect the bearing faults was used in [49] and [50]. The skew values of rectified data and the kurtosis values of the un-rectified data were used to detect the bearing fault. These results were independent of load and speed variations. In [50] statistical parameters (Crest Factor and Skew) were used to detect vibration and sound pressure signals to detect the bearing defects. Even beta distribution function was used in the same paper but it was inferred they did not prove to be very helpful in identifying different types of bearing defects.

The voltage induced along the shaft of a machine is an indication of the stator core or winding degradation. Shaft voltage has not yet proved to be a useful parameter for continuous monitoring because it is difficult to measure in a reliable way. Moreover, it has also been shown that any damage to the core or the winding would need to be substantial before a significant variation in shaft voltage occurred [51].The changes in the root mean square (rms) magnitude of Vsum (Vsum,rms) can reveal the presence and severity of turn-fault diagnostics where Vsum is the sum of instantaneous phase voltages. The maximum turn-fault sensitivity is obtained after band-pass filtering around the fundamental frequency [52].

\section{Frequency Domain Techniques (FD)}

In Frequency Domain Analysis frequency components and their amplitudes are used for detecting bearing faults. The Fast Fourier Transform (FFT) of signal is analyzed, which shows peaks and harmonics in the vibration spectra at the bearing defect frequency in the event of a fault. These peaks show a marked increase as the severity of the fault increases. When there are a large number of frequency 
components in the spectrum and the signal to noise ratio is low, it becomes difficult to distinguish between the faults and the noise components. This therefore, becomes a drawback. Envelope Analysis, also known as High Frequency Resonance Technique has been used to overcome this problem which has been studied in [53]. It is based on the concept that every time the raceway is hit by a localized defect; an impulsive force gets generated exciting the resonance of the mechanical system between the point of impact and the point of measurement. This method helps in getting the amplitude modulation of the resonance which lets the location and detection of the defect to be known. Stator fault monitoring techniques of induction motors were reviewed in [54]. A technique of signature analysis of the terminal voltage, immediately after switch-off to diagnose turn faults, was introduced in [55]. It concluded that the voltage unbalance of the source does not influence the result compared to online techniques using current signature analysis since the supply is off.

New condition monitoring techniques of stator inter-turn faults are being based on the frequency content of the transient line-to-line voltage after the motor is switched off and the transient voltage and currents during loading and unloading [56]. High frequency signal injection scheme was implemented in [57] for online stator winding fault diagnosis in inverter fed AC machines. A high resolution frequency estimation method for three phase induction machine fault detection was presented in [58]. A new method of obtaining diagnostic data from induction motors, derived from space vector angular fluctuations, was presented in [59]

\section{Time Frequency Domain Analysis (TFD)}

Time-Frequency Domain Analysis uses both time and frequency domain information to detect the transient features such as impact. There are a number of time-frequency domain techniques such as Short Time Frequency Transform (STFT), the Wigner-Ville Distribution (WVD) and the Wavelet Transform (WT). In cases where the signal to noise ratio is low and there is a presence of a lot of frequency components, these time-frequency domain techniques prove to be useful in detection of faults as explained in [60]. In [5], a solution for bearing outer race failure and faults due to stator voltage imbalances have been suggested, where the concept of machine modeling along with wavelet and symbolic dynamic analysis has been used for early detection of faults in an induction motor. Development of sensor fusion technique gives a probabilistic approach to these problems in induction motors. The method extends the D-Markov process to combine the information from both electrical and mechanical sensors. The vibration data that is obtained is analyzed using Continuous Wavelet Transform (CWT). There may be certain disadvantages of using CWT in analysis: 1) there is a problem of redundancy associated with CWT-the calculation of the wavelet transform is done by continuously shifting a continuously scalable function over a signal and calculating the correlation between them. These scaled functions do not give an orthogonal basis function and hence, result in redundancy. This may sometimes not be looked as a great disadvantage because making a signal orthogonal, reduces the Signal to Noise Ratio. 2) There are an infinite number of wavelets present in the wavelet transform which have to be reduced to a smaller amount for further analysis. 3) For most of the wavelet transform, analysis can be done only mathematically and hence it poses a limitation. This makes it necessary to use Discrete Wavelet Transform (DWT). But the use of DWT for analysis makes the signal no longer shift-invariant, which means that the time shifted version and the wavelet transform of the same signal are not shifted versions of each other. In [61], MultiResolution Analysis (MRA) using wavelet technique has been used to identify thermal degradation or degradation via electrical charge of the bearing, where an increase in the characteristic frequencies can be captured when the bearing undergoes degradation. The MRA calculates the general RMS trend for the measured vibration signals from the bearings. The higher frequencies dominate the signal when the motor becomes old and hence, gives 
an indication of bearing damage. The MRA therefore, gives the bearing information without distorting the original signal. Hence, this paper proposed a method to find the age of the three phase squirrel cage motor through analysis of the vibration spectra from the bearings. In [62], wavelet transform based bearing-localized defect detection has been presented, where wavelets are applied to detect the periodic structural ringing due to repetitive impulsive forces created when rolling element passes over a defect. This proposed a method which reduced the compromise on frequency resolution for time localization. Hybrid Park's Vector - NN Approach has been presented in [63] for on line fault diagnosis of induction motors. The results obtained provided a satisfactory level of accuracy. The well known Park's transformation has addressed a technique to get a twodimensional (2-D) representation of the three phase induction motor line currents. As a function of the three phase currents $\left(i_{a}, i_{b}\right.$ and $\left.i_{c}\right)$ the current Park's vector components $\left(i_{b}, i_{q}\right)$ are given as

$$
\begin{aligned}
& i_{d}=\sqrt{\frac{2}{3}} i_{c}-\frac{1}{\sqrt{6}} i_{b}-\frac{1}{\sqrt{6}} i_{c} \\
& i_{q}=\frac{1}{\sqrt{2}} i_{b}-\frac{1}{\sqrt{2}} i_{c}
\end{aligned}
$$

Under ideal conditions, balanced three phase currents lead to a Park's vector with the following components:

$$
\begin{aligned}
& i_{d}=\frac{\sqrt{6}}{2} I_{\max } \sin (\omega t) \\
& i_{q}=\frac{\sqrt{6}}{2} I_{\max } \sin \left(\omega t-\frac{\pi}{2}\right)
\end{aligned}
$$

Where, $\mathrm{I}_{\max }$ is the peak supply phase current, and The representation of the motor current Park's vector under healthy balanced operation is a circle centered at the origin of the coordinate axes. Under faulty operation, this pattern is deviated according to the associated fault [64]-[71].
Park's Vector approach was successfully used to detect stator winding faults in induction motors [64]. Under fault conditions, the Park's vector pattern became elliptic. The ellipticity of the pattern was proportional to the fault severity and its major axis orientation depended on the faulty phase. The relative thickness of the pattern was utilized to diagnose broken rotor bar faults in induction motors [65]. Under rotor static eccentricity faults in three-phase induction motors, the PVA pattern was recognized to have a distinctive shape [66]. The pattern was used to diagnose static rotor eccentricity more than $60 \%$ in both star and delta connected machines regardless of the load level as long as it is less than, or equal to, normal [67]. The extended Park's vector approach (EPVA) utilized the spectral component of the ac level of the Park's vector pattern at twice the supply frequency to diagnose stator winding faults in three-phase synchronous and asynchronous motors [68]. In case of inverter-fed induction motor drives, the healthy operation pattern of PVA is not circular; however, distinguishable deviations in the pattern could be used to diagnose faults in the power electronic components of the drive control [69], [70]. Direction of orientation of the pattern was an effective index to define any short or open circuit fault on one semiconductor switch. The technique was extended appropriately to account for electronic component faults in full converter DC motor drives [71]

The diagnostics for induction motors' incipient fault detection pertaining to motor current signature analysis (MCSA) have been extensively dealt in a number of researches [72]-[80]. The MCSA utilizes the results of the spectral analysis of the stator current of an induction motor to pinpoint an existing or incipient failure of the motor or driven system using the sequence components of current, radio-frequency (RF) component of neutral current, and shaft currents. Two widely used techniques i.e. motor current spectrum analysis and multiple reference frame theory were employed in [81], [82]

\section{E. Higher Order Spectra Analysis (HOS)}


Higher Order Spectra Analysis which describes the degree of correlation among different frequencies present in the signal can also be used for fault detection. When there are large values of phase correlation among the harmonics of defect frequency, it indicates some bearing fault. Bi-coherence has been used for analysis in a couple of research works which helps in extraction of the features determining the condition of the bearing. Bi-coherence has been used to find the degree of phase correlation among any three harmonics of the bearing characteristic defect frequencies. Motor bearing diagnosis by fundamental frequency amplitude based fuzzy decision system was employed in [83].

One of the novel and effective Digital Signal Processing (DSP) tools used for feature extraction of the machine performance characteristic signals is the HOS. The HOS technique has been applied in various researches during 1990's [84]-[89] to address practical problems after receiving great theoretical interests. Advantages of estimating HOS third and above measures are summarized in [84], as follows.

- Additive Gaussian noise is automatically suppressed.

- Non-minimum phase systems can be identified.

- Information due to deviations from Gaussianity can be extracted.

- Nonlinear systems can be detected and identified.

A comparison of signal processing based techniques for detection of broken rotor bars and bearing deterioration in induction motors was presented in [90]. Features of those techniques relevant to fault detection were also presented. Those features were then analyzed and compared to deduce wavelet as the most appropriate technique for induction motor rotor fault detection. For line-connected machines, the negative-sequence current is the fundamental fault signature for a winding fault. The theoretical basis for this approach was presented in [91], wherein the authors derived a mathematical model for a machine with shorted turns in the stator winding. In later works, secondary fault signatures such as negativesequence impedance [92], double line- frequency component of instantaneous threephase power, or torque [93] have also been proposed for fault detection. Turn-fault detection based on monitoring the axial leakage component of flux [94] and electrically excited vibrations [95] have also been proposed; however, the sequence component approach provides a better signal-to-noise ratio, is easier to measure, and does not require any special instrumentation besides current sensors. The sensitivity of sequence-components-based turnfault detection schemes depends on the extent to which the effects of non-idealities are compensated. The negative sequence current is affected by unbalance in the power supply and inherent asymmetries in the machine and instrumentation. Experimental evidence has been obtained in [96] to show that the negativesequence current due to asymmetries, is slip dependent. Experimental investigations for condition monitoring of stator windings in induction motors using effective negative sequence impedance detector, voltage mismatch detector and also situations where motor construction imperfections exist and mechanical loads are unpredictable, has been presented in [97]-[103]. A new technique exploring pendulous oscillation property for induction machine broken rotor bar fault diagnosis using the rotor magnetic field space vector orientation has been implemented in [104]-[106]. Simplified axial leakage flux spectrum method for detection of incipient stator-inter-turn short circuits in induction machine has been aptly demonstrated in [107]-[110]. Study proposed in [111] dealt with induction machine condition monitoring using higher order spectra. The method could detect the type and magnitude of fault unambiguously. Electrically excited vibrations were used in [112] to investigate the status of stator winding integrity.

F. Artificial Intelligence (AI) Based Techniques (AI)

The artificial intelligence (AI) is the study of system conditions through the use of computational models. The AI tools are of great practical significance in engineering to solve various complex problems, which require human intelligence. Recently, significant efforts have been made on the use of artificial 
intelligence tools to develop condition monitoring and faults diagnostic techniques for electric machines. An expert system (ES) based on the knowledge representation for faults diagnosis of induction motors has been outlined in [113]. The knowledge based ES uses instantaneous line currents, line voltages, and rotor speed as input variables. In [114], an online real time ES for diagnosing faults in induction motors has been presented. The knowledge base consists of a failure tree, an observation tree, and a case tree. The proposed ES require theoretical and practical studies of fault mechanisms, and case histories of fault analyses. This method is vulnerable to uncertainty and is not quite suitable from computational point of view. Pöyhönen et al. in [115], have implemented support vector machine (SVM) based faults diagnostic and classification technique for an inverter fed squirrel cage induction motor. The magnetic field analysis is used to get virtual data of the healthy and faulty operating conditions of the induction motor. The power spectra of stator current are used as inputs to the SVM based classifier to distinguish healthy condition from normal un-faulted condition. However, the technique may fail if two separate classes get equal amount of votes. In addition, it did not consider the possible redundancy from pairwise outputs of the classifier.

A three-layer feed forward neural network for condition monitoring of induction motors in real time has been implemented in [116] using 35 training and 70 testing data patterns set. The stator inter-turn and motor bearing faults are investigated at constant load torque. The stator currents and rotor speed are used as inputs during the off-line training of the network. The network is implemented in real time using a digital signal processor board. The network showed satisfactory performances with higher number of hidden nodes. However, the technique is not quite accurate due to the dynamic nature of machine parameters. In addition, it requires large number of training data set in order to cover all the operating conditions including the faulted and un-faulted conditions of the motor. Lasurt et al. in [117] have implemented a fuzzy logic based condition monitoring and faults diagnostic technique for induction motors. The proposed technique implemented the higher order spectral (HOS) analysis of the machine vibration signal. The fuzzy logic procedures are then applied to the HOS signatures in order to enable diagnosis of a machine fault. An adaptive neural fuzzy inference system (ANFIS) based faults diagnostic technique for an inverter fed pulse width modulated induction motor drive system has been proposed in [118]. The proposed technique involves data acquisition and feature extraction of fault currents, and then use of adaptive neural fuzzy inference system (ANFIS) for faults diagnostic. The technique used the mean values of direct and quadrature axis phase currents as the input pattern for the ANFIS. The major drawback of conventional Artificial Neural Network (ANN) fault detection is the inherent black box approach that can provide the correct solution, but does not provide heuristic interpretation of the solution. The above problem was overcome in [119] using a neural network structured upon fuzzy logic principles. The fuzzy membership function module provided the qualitative heuristic knowledge of the motor current and rotor speed. However, to accomplish the objective with more accurate results, in addition to stator current and rotor speed, three more easily measurable parameters; winding temperature, bearing temperature, and noise of motor $(\mathrm{dB})$ were considered in [120]. The inferences about insulation level and bearing condition were drawn on the strength of 108 training and 36 testing data patterns. In [121] fuzzy logic approach and in [122], adaptive neural fuzzy inference system is applied for same type of fault detection. A comparative analysis of incipient fault detection techniques like ANN, Fuzzy Inference System (FIS) and ANFIS with five input parameters; was presented in [123]. It was concluded that an ANFIS based detector provided the highest accuracy in prediction of bearing condition.

Use of Genetic Algorithm (GA) has been suggested to evolve architectures and weights of neural networks in [124]. Stator winding interturn short circuit have been successfully detected by Evolutionary Artificial Neural 
Network (EANN). Performance comparison on correct fault detection and memory requirements provided by EANN and alternative nonlinear modeling techniques showed that EANN outperformed its counterparts. The objective of stator winding turn-fault detection is to diagnose a fault before failure of insulation between winding and ground. Some of the methods surveyed here have been shown to be sensitive to a fault involving only $1 \%$ of the turns [125]-[127]; however, the fault detection schemes have been tested on specially rewound machines with fault conditions simulated by externally shortcircuiting tapped turns of the winding. However, not much information is available on how quickly a winding fault progresses from an inter-turn fault involving a few turns to a catastrophic ground fault. Hence, experimental tests are required to obtain an estimate of the time to-disaster. The test reported in [127] is a step in this direction. Further research and testing is required toward the development of a commercially implementable scheme.

A novel on-line neural network based diagnostic scheme, for induction machine stator winding turn fault detection, was presented in [128]. The scheme consisted of a feed-forward neural network combined with a Self-organizing Feature Map (SOFM) to visually display the operating condition of the machine on a twodimensional grid. The operating point moves to a specific region on the map as a fault starts developing and can be used to alert the motor protection system to an incipient fault. This is a useful tool for commercial condition monitoring systems. Experimental results were provided, with data obtained from a specially wound test motor, to illustrate the robustness of the proposed turn fault detection scheme. The new method was not sensitive to unbalanced supply voltages or asymmetries in the machine and instrumentation. Three novel and selfcommissioning training algorithms were proposed by authors of [129] for on-line training of a feed-forward NN to effectively address the shortcomings in NN earlier diagnostic methods. Experimental results are provided for an induction machine stator winding turn-fault detection scheme, to illustrate the feasibility of the proposed on-line training algorithms for implementation in a commercial product. LabVIEW environment was implemented in [130] for induction machine online stator fault diagnosis. Accelerated and unsupervised insulation failure conditions were diagnosed using NN based turn fault detection scheme in [131]-[133]. Multiple discriminant analysis and $\mathrm{NN}$ based monolith and partition fault detection schemes for broken rotor bars was presented in [134]. Rotor eccentricity faults in closed loop drive connected induction motor were successfully implemented in [135], using ANN. AI techniques in induction machines diagnosis including the ripple effect was studied in [136], [137]. Concordia based fuzzy decision system was implemented in [138] to diagnose stator faults.

\section{Futuristic Trends (hybrid Techniques): Improvisations or Integration of Two or More Methods}

Despite various techniques elaborated in Section IV for the monitoring and fault detection of induction motors from traditional techniques to most recent $\mathrm{AI}$ techniques in recent years, the domain of fault diagnosis is still being thronged with ambitious studies continuously piling up paving way for technological up-gradation. The very latest trend shows integration of two or more of earlier methods minimizing complications like user expertise. The techniques of fault detection and diagnosis uptill 2011 were based on a qualitative interpretation of the results needing user expertise. Complications of implementation of those methodologies were eased out in a number of research studies conducted during the year 2012 and 2013. Hence, to give adequate representation to futuristic trends in the domain of incipient fault detection, and diagnosis, very recent papers published in the year 2012 and 2013 up till September, depicting the current trends and future scope, have been cited below. 
In [139], an integral methodology combining the DWT with the scale transform for feature extraction and correlation coefficient for pattern recognition was employed to diagnose the presence of rotor bar failure in an automatic way. Bearing fault model for induction motor with externally induced vibrations was aptly implemented in [140]. Relationship between vibration and current in IM operated under external vibrations was investigated focusing on air-gap variation model. During tests, both stator phase currents and vibration of the machine were sampled. A novel hybrid featurereduction methodology was proposed as a contribution to the induction motor load independent fault classification in [141]. This model employed on a $5.5 \mathrm{~kW}$ induction motor, depended on two parameters, namely, the smoothing kernel used to derive a) the features and b) the distance measurement. Identification of broken rotor bars and its severity was diagnosed using winding function method (WFM) in [142]. The classical multiple signal classification (MUSIC) method used for induction machine fault detection has the disadvantage that it can extract meaningful frequencies but cannot give accurate amplitude information of fault harmonics. This drawback was removed in [143] using a frequency estimator, an amplitude estimator, and a fault decision module. An artificial ant clustering technique to detect broken rotor bars and bearing failures at different load levels was implemented in [144] on a $5.5 \mathrm{~kW}$ squirrel cage IM. The behavior of the newly developed expressions of the symmetrical components, verified experimentally on a $1.1 \mathrm{~kW}$ IM under different frequencies and load conditions to detect stator faults, was demonstrated in [145]. In [146], a general load torque model was proposed such that the model took into account the higher order terms of torque variations by considering the impulse train function instead of sinusoidal function. Firstly, the stator current due to torque variations under bearing fault was analyzed, and then the numerical simulation was performed to verify the accuracy of the model. Characterization and classification of the harmonics present in a healthy cage rotor induction motor spectrum as a starting point for diagnosis was presented in [147]. The traditional Hilbert method to detect broken rotor bar faults was reviewed in [148]. The drawbacks associated with it were removed using estimation of signal parameters via rotational invariance technique (ESPIRIT). Influences of the broken rotor bar faults on electromagnetic characteristics of the IM, was presented in [149]. Monitoring of electromagnetic torque was also suggested.

Eccentricity related faults are very common in induction motors. Traditional diagnostic methods cannot offer reliable results for principal slot harmonics (PSH) in induction motors. Also most of the works are focused upon dynamic and mixed eccentricities. In [150], the finite element method (FEM) simulations and experimental testing was proposed to detect static eccentricity. An extension to this method was observed in [151], in which a specific time frequency decomposition tool, the Zhao-Atlas-Marks distribution was proposed. Results proved the ability of the approach to complement the information obtained from the current analysis. In [152], a data fusion-based misalignment related fault identification algorithm was presented, which isolated fault features from similar features generated because of other operating conditions. Static eccentricity fault detection was presented in [153] by applying distinctive methods of wavelet packet decomposition for distorted current, and gyration radius for torque signals. In this study finite element (FEM) was used for modeling of induction motor before and after rotor eccentricity fault. Both the methods were observed to be consistent and reliable in eccentricity fault detection and also could be used to measure the severity degrees of the fault. With the passage of time, new techniques and methods for detection of induction motors' incipient faults kept on emerging. These techniques and methods are either improvisations on earlier methods removing their limitations, ambiguity, and drawbacks; or 
combination of distinctive techniques exploiting the advantages of individual techniques. A new technique based on a recent enhancement on wavelets known as complex wavelet (CW) was proposed for or identifying multiple faults in vector controlled induction motor drives [154]. In this study; radial, axial and tangential vibrations were analyzed for diagnostic purpose. Initially, threshold based method was applied under variable frequency and load conditions. Later on, the feature extraction and classifier modeling were discussed, in which nearly shift-invariant $\mathrm{CW}$ based model was compared with DWT for detecting the faults such as inter-turn, inter-turn faults under progression and bearing damage. A novel non-intrusive approach for detecting outer-race bearing defects using stator current signal, was developed in [155]. In this study, the empirical mode decomposition (EMD) technique was applied for extracting intrinsic mode functions (IMFs), which were applied on wigner-ville distribution (WVD). The experimental results showed that stator current based monitoring yielded a high degree of accuracy. Non-intrusive sensor-less speed estimation technique using MCSA has been employed in [156] and [157] to compute slip in an attempt to track the inter-turn fault component autonomously under different loadings and operating frequencies. This offered possibility of incorporating above technique to inverter-fed machines in future. Detection and diagnosis of broken rotor bars is associated with no practical solution to the air duct-induced false indications regarded as the on-going problem in the field. The experimental attempt carried on a $6.6 \mathrm{kV}$ motor [158], showed that the magnitude of the 2 sfs component due to axial ducts depend on the design, material, construction, and operating conditions of the motor. It is also shown that the 2 sfs component can even decrease with broken bars. An experimental study on a $7.5 \mathrm{Hp}$ induction motor under controlled eccentricity conditions verified that the sensitivity of offline eccentricity detection can be significantly improved compared to earlier methods [159].
The fault detection and diagnosis was achieved through a controllable impedance using ANN. In this method [160], the fault tolerance was obtained by controlled neutral grounding resistor. This allowed for continuous free operation of the induction motor even with stator winding faults. Detection and localizing the broken bar faults was studied in [161], using MCSA combined to SVM. In this study it was proposed to classify the feature vectors extracted from the magnitude of spectral analysis using multi-class SVM to discriminate the state of motor. Core vibrations in the axial direction were investigated in [162] to overcome the limitations of the classical techniques using time-frequency analysis. The DWT approach presented is best suited for automotive or high power traction systems, in which safe operating and availability are mandatory. In [163], a distinctive method combining WT and ANN for detection of short circuits in stator winding and faulty bearing in induction motor, under different load level, has been presented. Ad-q model of induction motor for estimation of parameters in a three phase induction motor due to broken rotor bars, which causes electrical and magnetic asymmetry, has been presented in [164]. The asymmetry was reflected as pseudo-saliency through different resistances and inductances in both axes. When multiple faults exist in a machine, vibration and current are excited by several fault related frequencies combined with each other, linearly or non-linearly. Accuracy, reliability of fault detection were set as objectives in the study using higher order spectral analysis [165], with single or multiple faults present. In above review several works have been found dealing with vibration and current analysis for monitoring and detection of faults. But, the analysis of sound signals has not been sufficiently explored as an alternative noninvasive monitoring technique. The contribution of investigation in [166] was development of a strategy for reliable assessment of a specific fault condition in an induction motor through the analysis of sound using intrinsic mode functions (IMFs) and the 
Fast Fourier Transform (FFT). For preventing any consequent large fault developed from an initially small fault, a novel method of direct detection of multi-turn fault of IM by direct detection of asymmetry admittance component was presented in [167]. In this method first the negative sequence component which comes from structural asymmetry caused by a sudden winding fault was detected by the least square (LS) fitting and diagnosis index named as asymmetry admittance

A radial basis function (RBF) neural network based on immune genetic algorithm (IGA) was applied in [175]. The experiments showed that for motor fault diagnosis problem, the result of RBF neural network based on IGA are significantly better than direct result of RBF neural network. Good inner adaptability of ANN has warranted its extensive application in fault diagnosis systems. Among the various ANN, the back-propagation (BP) algorithm is one of the most important and widely used algorithms and has been successfully applied in many fields. However, the conventional BP algorithm suffers from a few shortcomings, such as slow convergence rate and easily sticking to a local minimum. Hence, improvisations on BP algorithm are the most sought. The paper [176] presented a new BP which was based on particle swarm optimization (PSO) algorithm for detecting rotor failures in cage motors. Theoretical development based on magneto-motive forces approach shows the modulation effect of mechanical unbalance on rotor current expressions. Because a real load is not ideal and presents an intrinsic rotor asymmetry involving an additional time varying torque according to its rotor position, the stator motor current spectral harmonics produced by the load will overlap the harmonics caused by the rotor unbalance since induction machine becomes sufficiently loaded. Thus, the authors in [177] examined detection of such machine defect by analysis of stator current spectrum of a squirrel cage induction motor running under unloaded and loaded condition. Authors in [178] adopted a distinct non-linear model for detection of broken rotor bars problem using residual generators based in moving horizon estimator of the rotor resistance and the reconfiguration action where the failure events are detected by jumps in the estimated parameter values of the model. The machine used was $1.1 \mathrm{~kW}$, 220/380V, 50

- Research trends show that two or more integrated AI techniques will have a greater role in motor diagnostic system to account for higher level of accuracy and classification of faults.

- $\quad$ Self-repairing electrical drives based upon intelligent systems like GA algorithm-assisted ANN, FIS and ANFIS will find extensive place in near future.

- Higher level of precision in measurements corresponding to accuracy in detection and classification of various faults, specifically when two or more faults (bearing/end rings defect, shaft non-alignment, rotor touching stator, air-gap eccentricity, broken bars etc) are present simultaneously is the identified need.

- Electric motor drive system functions on the principle of electro-magnetism. Thus, the effects of magnetic saturation on voltage and current signatures in the event of fault need to be decomposed in upcoming research work for finding the severity.

- Stator winding faults are observed to be emanating from degradation of insulation system. Thus, a self monitoring system detecting the deterioration of insulation need to modeled. Such model should be able to detect the aging and residual life of the insulation system.

- Insulation system deterioration takes place because of a number of causes which may be mechanical or electrical. 
The model envisaged above, should be able to accurately pinpoint the various causes of insulation degradation so that cause can be attended before leading to failure.

- User friendly/cost effective techniques and diagnostic tools which do not require high level of technical expertise should replace today's high-tech detection and diagnostic methods.

\section{Conclusions}

An in-depth review of induction motors' incipient fault detection and diagnostic methods focusing on faults related with stator winding, bearing, air-gap eccentricity, and broken rotor bars, classified according to various techniques, have been presented here giving the state-of-art in fault diagnosis domain. A separate section 'Futuristic Trends' is devoted to review of most recent researches conducted during the year 2013 up-till September. Application of two or more methods integrated together with major role of AI techniques, for enhancing the accuracy of detection and classification has also been discussed under section V. Seven recommendations for future research studies have also been put up in the same section. After reviewing one hundred and eighty research papers, it is concluded here that the incipient fault detection and diagnostic techniques employed in case of low voltage induction motors, are not only costly but required high level of technical expertise as well. Design and development of online user-friendly/costless detection and diagnostic method therefore, has been undisputedly emerged as the immediate industry need which should be explored extensively in futuristic researches.

\section{References}

[1] Peter Vas, "Parameter estimation, condition monitoring, and diagnosis of electrical machines", Clarendon Press Oxford, 1993.
[2] P. J. Tavner and J. Penman, "Condition monitoring of electrical machines", Hertfordshire, England: Research Studies Press Ltd, ISBN: 0863800610, 1987.

[3] H. W. Penrose, "Test methods for determining the impact of motor condition on motor efficiency and reliability", ALL-TEST Pro, LLC, Old Saybrook, CT., Mar. 2007.

[4] "Report of large motor reliability survey of industrial and commercial installations, part I \& II," IEEE Transactions on Industry Applications, pp. 853-872, July 1985.

[5] R. Fiser and S. Ferkolj, "Application of finite element method to predict damaged induction motor performance," IEEE Transactions on Magnetics, Vol. 37, No. 5, pp. 3635-3639, Sep. 2001.

[6] R.Samsi, "A probabilistic framework for fault detection in induction motors," Ph.D. dissertation, Tthe Pennsylvania State University, 2006.

[7] J.R.Deller, "Set membership identification in digital signal processing ", IEEE ASSP Magazine, Vol. 6, No. 4, pp. 4-20, October 1989.

[8] J. Deller, M. Nayeri, and S. Odeh, "Least-Square Identification with Error Bounds for Real-Time Signal Processing and Control," Proceedings of the IEEE, Vol. 81, No. 6, pp. 815-849, Jun. 1993.

[9] M. F. Cheung, S. Yurkovich, and K. Passino, "An optimal volume ellipsoid algorithm for parameter set 
estimation," IEEE Transactions on Automatic Control, Vol. AC-38, No.8, pp. 1292-1296, Aug. 1993.

[10] A. Vicino and G. Zappa, "Sequential approximation of feasible parameter sets for identification with set membership uncertainty," IEEE Transactions on Automatic Control, Vol. 41, pp. 774-783, Sep. 1996.

[11] M. O. Mustafa, G. Nikolakopoulos, and T. Gustafsson, "A survey on modeling approaches for three phase induction motors," Proceedings of the IASTED International Conference on Modeling, Simulation and Identification, pp. 336-343, 2011.

[12] Peter Vas, Electrical Machines and Drives, O. S. PUBLICATION, Ed., 1992.

[13] A. Sarkar and G. Berg, "Digital simulation of three-phase induction motors", IEEE Transactions on Power Apparatus and Systems, Vol.89, No. 6, pp. 1031-1037, July/August 1970.

[14] S. Chen and R. Zivanovic, "Modelling and simulation of stator and rotor fault conditions in induction machines for testing fault diagnostic techniques", European Transactions On Electrical Power, Vol.20, pp. 611 -629, April 2009.

[15] K. Sandhu and V. Pahwa, "Sumilation study of three phase induction motor with variation in moment of inertia", ARPN Journal of Engineering and Applied Sciences, Vol.4, No.5, pp.72-77, August 2009.

[16] O. Hasan, "Fault detection, diagnosis and prognosis of rolling element bearings: Frequency domain methods and hidden markov modeling", Ph.D. dissertation, Case Western Reserve University, 2004.

[17] A. Bellini, F. Filippetti, G. Franceschini, C. Tassoni, and G. Kliman, "Quantitative evaluation of induction motor broken bars by means of electrical signature analysis", IEEE Transactions on Industry Application, Vol.37, No. 5, p. 1248-1255, 2001.

[18] F. C. Trutt, "Steady state analysis of wound-rotor induction machines with simultaneous stator and/or rotor faults", Elect. Mach. Power Syst., Vol. 16,pp. 35-48, 1989.

[19] X. Luo, Y. Liao, H. A. Toliyat, A. ElAntably, and T. A. Lipo, "Multiple coupled circuit modeling of induction machines", IEEE Trans. Ind. Appl., Vol. 31, No. 2, pp.311-318, Mar./Apr. 1995.

[20] Y. Zhaoand T. A. Lipo, "Modeling and control of a multi-phase induction machine with structural unbalance", IEEE Trans. Energy Convers., Vol. 11, pp. 578-584, Sep. 1996.

[21] D. Bispo, L. M. Neto, J. T. de Resende, and D. A. de Andrade, "A new strategy for induction machine modeling taking into account the magnetic saturation", IEEE Trans. Ind. Applicat., Vol. 37, No. 6, pp. 1710-1719, Nov./Dec. 2001.

[22] D. Henry, A. Zolghadri, M. Monsion, and F. Cazaurang, "Fault diagnosis in induction machines using the generalized structured singular value", Control Eng. Practice, Vol. 10, pp. 
587-598, 2002.

[23] R. M. Tallam, T. G. Habetler, and R. G. Harley, "Transient model for induction machines with stator winding turn faults", IEEE Trans. Ind. Appl., Vol. 38, No. 3, pp. 632-637, May/Jun. 2002.

[24] A. J. M. Cardoso, S. M. A. Cruz, J. F. S. Carvalho, and E. S. Saraiva, "Rotor cage fault diagnosis in three-phase induction motor by Park's vector approach", in Proc. IEEE-IAS Annu. Meeting, 1995, pp. 642-646.

[25] J. L. Kohler, J. Sottile, and F. C. Trutt, "Online condition monitoring of induction motors", IEEE Trans. Ind. Appl., vol. 38, no. 6, pp. 1627-1632, Nov./Dec. 2002.

[26] J. L. Kohler, J. Sottile, and F. C. Trutt, "Application of online voltage mismatch condition monitoring of induction motor stator windings in a mining environment", in Conf. Rec. 38th IEEE IAS Annu. Meeting, Oct. 12-16, 2003, vol. 3,pp. 1637-1644.

[27] S. B. Lee, R. M. Tallam, and T. G. Habetler, "A robust, on-line turn fault detection technique for induction machines based on monitoring the sequence component impedance matrix", IEEE Trans. Power Electron., vol. 18, no.3, pp.865-872,May 2003.

[28] B. Mirafzal and N. A. O. Demerdash, "Induction machine broken-bar fault diagnosis using the rotor magnetic field space vector orientation," in Conf. Rec. 38th IEEE IAS Annu. Meeting, Oct. 12-16, 2003, vol. 3, pp. 1847-1854.

[29] B. Mirafzal and N. A. O. Demerdash,
"Effects of load on diagnosing broken bar faults in induction motors using the pendulous oscillation of the rotor magnetic field orientation", in Conf. Rec. $39^{\text {th }}$ IEEE IAS Annu. Meeting, Oct. 3-7, 2004, vol. 2, pp. 699-707.

[30] B. Mirafzal, R. J. Povinelli, and N. A. O. Demerdash, "Interturn fault diagnosis in induction motors using the pendulous oscillation phenomenon," IEEE Trans. Energy Convers., vol. 21, no. 4, pp. 871-882, Dec. 2006.

[31] B. Q. Xu, H. M. Li, and L. L. Sun, "Detection of stator winding inter-turn short circuit fault in induction motors", in Proc. Int. Conf. Power Syst. Technol. (PowerCon), Nov. 21-24, 2004, vol. 2, pp. 1005-1009.

[32] J. Penman, H. G. Sedding, B. A. Lloyd, and W. T. Fink, "Detection and location of inter-turn short circuits in the stator windings of operating motors," IEEE Trans. Energy Convers., vol. 9, no. 4, pp. 652-658, Dec. 1994.

[33] T. Assaf, H. Henao, and G. A. Capolino, "Simplified axial flux spectrum method to detect incipient stator inter-turn short-circuits in induction machine", in Proc. IEEE Int. Symp. Ind. Electron., May 4-7, 2004, vol. 2, pp. 815-819.

[34] B. Ayhan, M. Y. Chow, and M. H. Song, "Multiple discriminant analysis and neural-network-based monolith and partition fault-detection schemes for broken rotor bar in induction motors," IEEE Trans. Ind. Electron., vol. 53, no. 4, pp. 1298-1308, Jun. 2006. 
[35] S. H. Kia, H. Henao, and G. A. Capolino, "A high-resolution frequency estimation method for three-phase induction machine fault detection," IEEE Trans. Ind. Electron., vol. 54, no. 4, pp. 2305-2314, Aug. 2007.

[36] H. Xianghui, T. G. Habetler, and R. G. Harley, "Detection of rotor eccentricity faults in a closed-loop drive-connected induction motor using an artificial neural network," IEEE Trans. Power Electron., vol. 22, no. 4, pp. 1552-1559,Jul. 2007.

[37] B. Liang, B. S. Payne, A. D. Ball, and S. D. Iwnicki, "Simulation and fault detection of three-phase induction motors ", Math. Comput. Simul., pp. 1-15, Nov. 2002.

[38] D. Dolinar, R. D.Weerdt, R. Belmans, and E. M. Freeman, "Calculation of twoaxis induction motor model parameters using finite elements", IEEE Trans. Energy Convers., Vol. 12, No. 2, pp. 133-140, Jun. 1997.

[39] R. R. Schoen and T. G. Habetler, "A new method of current-based condition monitoring in induction machines, operating under arbitrary load conditions," Elect. Mach. Power Syst., Vol.25,pp. 141-152, 1997.

[40] H. R. Martin and F. Honarvar, "Application of statistical moments to bearing failure detection," Vol. 44, 1995, pp. 67-77.

[41] R. B. W. Heng and M. J. M. Nor, "Statistical analysis of sound and vibration signals for monitoring rolling element bearing condition," Vol. 53,
1998, pp. 211-226.

[42] P. D. McFadden and J. D. Smith, "Vibration monitoring of rolling element bearings by high frequency resonance technique-a review," Vol. 77, 1984, pp. 3-10.

[43] I. Howard, "A review of rolling element bearing vibration: Detection, diagnosis and prognosis,"1994.

[44] E. A. Seyfettin, "Multisensor fusion for induction motor aging analysis and fault diagnosis", Ph.D. dissertation, The University of Tennessee, 1999.

[45] C. J. Li and J. Ma, "Wavelet decomposition of vibrations for detection of bearing localized faults", Vol. 30, 1997,pp. 143-149.

[46] G. Godi, B. Li, M. Y. Chow, and J. C. Hung, "Motor bearing diagnosis by a fundamental frequency amplitude based fuzzy decision system", Vol. 4, 1998, pp. 1961-1965.

[47] F. Filippetti, G. Franceschini, M. Martelli, and C. Tassoni, "An approach to a knowledge representation about induction machine diagnostics in expert systems", Proceedings Conference Record of International Conference on Electric Machines (ICEM), Vol. 3, pp. 289-296, Pisa, Italy, September 1988.

[48] D. Leith, N. D. Deans, and L. I. D. Stewart, "Condition monitoring of electrical machine using real-time expert systems", Proceedings Conference Record of International Conference on Electric Machines (ICEM), Vol. 3, pp. 297-302, Pisa, Italy, September 1988. 
[49] S. Pöyhönen, M. Negrea, A. Arkkio, H. Hyötyniemi, and H. Koivo, "Fault diagnostics of an electrical machine with multiple support vector classifiers", Proceedings of IEEE International Symposium on Intelligent Control (ISIC), Vol. 1, pp. 373-378, Vancouver, BC, October, 2002.

[50] Mo-Yuen Chow, Peter M. Mangum, Sur Oi Yee, "A Neural Network Approach to Real Time Condition Monitoring of Induction Motors", IEEE transaction on Industrial Electronics, Vol.38, No.6, Dec. 1991, pp. $448-453$.

[51] I. Lasurt, A. F. Stronach and J. Penman, "A fuzzy logic approach to the interpretation of higher order spectra applied to fault diagnosis in electrical machines", Proceedings Conference Record of North American Fuzzy Information Processing Society (NAFIPS) Annual Meeting, pp. 158-162, Atlanta, GA, 13-15 July 2000.

[52] J. Park, D. Kim, S. Kim, D. Lee, and M. Chum, " $C$-ANFIS based fault diagnosis for voltage-fed PWM motor drive systems", Proceedings Conference Record of North American Fuzzy Information Processing Society (NAFIPS) Annual Meeting, Vol. 1, pp. 379-383, Banff, AB, 27-30 June 2004.

[53] Paul V. Goode and Mo-Yuen Chow, "Using a neural/fuzzy system to Extract Heuristic Knowledge of Incipient Faults in Induction Motors: Part I and II", IEEE Transaction on Industrial Electronics, Vol.42, No.2, April 1995, pp.131-146.

[54] M. S. Ballal, H. M. Suryawanshi, and M.
K. Mishra, "ANN based system for the detection of winding insulation condition and bearing wear in single phase induction motor", J. of Electrical Engineering \& Technology, Vol. 2, No. 4,pp. 485 - 493, 2007.

[55] M. S. Ballal, Z. J. Khan, H. M. Suryawanshi and R. L. Sonolikar, "Induction Motor: Fuzzy System for the detection of winding insulation condition and bearing wear", Electric Power Components and System, Vol. 34, No. 2, Feb. 2006, pp. 159-171.

[56] M. S. Ballal, Z. J. Khan, H. M. Suryawanshi and R. L. Sonolikar, "Adaptive neural fuzzy inference system for the detection of inter-turn insulation and bearing wear fault in induction motor", IEEE Transaction on Industrial Electronics, Vol. 54, No. 1, Feb. 2007, pp.250-258.

[57] M. S. Ballal, H. M. Suryawanshi, and M. K. Mishra, "Detection of incipient faults in induction motors using FIS, ANN and ANFIS techniques", J. of Power Electronics, Vol. 8, No. 2, pp. 181 - 191, 2008.

[58] D. F. Leite, R. Attux, F. Von Zuben, P. Costa Jr., and F. Gomide, "Evolutionary neural network applied to induction motors stator fault detection", 978-14244-4252-2/09, IEEE.

[59] Hamid Nejjari and Mohamed EI Hachemi Benbouzid, "Monitoring and diagnosis of induction motors electrical faults using a current park's vector pattern learning approach", IEEE transactions on industry applications, Vol. 36, No. 3, May/June 2000. 
[60] Arfat Siddique, G. S. Yadava, and Bhim Singh, "A review of stator fault monitoring techniques of induction motors", IEEE Transactions on Energy Conversion, Vol. 20, No. 1, March 2005, pp. $106-114$.

[61] S. Nandi and H. A. Toliyat, "Novel frequency-domain-based technique to detect stator inter-turn faults in induction machines using stator induced voltages after switch-off', IEEETrans.Ind.Appl.,Vol.38, No.1, pp.101-109,Jan./Feb. 2002.

[62] A. Bellini, A. D. Carli, and M. A. Cava, "Parameter identification for inductionmotor simulation", Automatica, Vol. 12, pp. 383-386, 1976.

[63] A. K. Chattopadhyay and T. J. Rao, “ $A$ generalized method of computer simulation for induction motors with stator current discontinuities and its application to a cycloconverter-fed drive", IEEE Trans. Ind. Appl., Vol. IA16, No. 2, pp. 234-241, Mar./Apr. 1980.

[64] T. A. Lipo and A. Consoli, "Modeling and simulation of induction motors with saturable leakage reactances", IEEE Trans. Ind. Appl., Vol. IA-20, No. 1, pp. 180-189, Jan./Feb. 1983.

[65] J. Faiz and A. R. Seifi, "Dynamic analysis of induction motors with saturable inductances", Elect. Power Syst. Res., Vol. 34, pp. 205-210, 1995.

[66] B. Laporte, G. Vinsard, and J. C. Mercier, "A computation method for induction motors in steady-state" Math. Comput. Simul., Vol. 38, pp. 369-376,
1995.

[67] M. A. Cash, T. G. Habetler, and G. B. Kliman, "Insulation failure prediction in induction machines using lineneutral voltages", in Proc. IEEE Ind. Applicat. Soc. Annu. Meeting, vol. 1, Oct. 1997, pp. 208-212.

[68] A. Bethge, P. K.-W. Lo, J. T. Phillipson, and J. R. Weidner, "On-line monitoring of partial discharge on stator windings of large rotating machines in the petrochemical environment", IEEE Trans. Ind. Appl., vol. 34, no. 6, pp. 1359-1365, Nov./Dec. 1998.

[69] C. M. Riley, B. K. Lin, T. G. Habetler, and R. R. Schoen, "Amethodfor sensor less on-line vibration monitoring of induction machines", IEEE Trans. Ind. Appl., vol. 34, no. 6, pp. 1240-1245, Nov./Dec. 1998.

[70] S. Nandi and H. A. Toliyat, "Novel frequency-domain-based technique to detect stator interturn faults in induction machines using stator-induced voltages after swich-off', IEEE Trans. Ind. Appl., vol. 38, no. 1, pp. 101-109, Jan./Feb. 2002.

[71] N. Arthur and J. Penman, "Induction machine condition monitoring with higher order spectra", IEEE Trans. Ind. Electron., vol. 47, pp. 1031-1041, Oct., 2000.

[72] M. E. H. Benbouzid, H. Nejjari, R. Beguenane, and M. Vieira, "Induction motor asymmetrical faults detection using advance signal processing techniques", IEEE Trans. Energy Conversion, vol. 14, pp. 147-152, June 
1999.

[73] M. E. H. Benbouzid, M. Vieira, and C. Theys, "Induction motors' faults detection and localization using stator current advanced signal processing techniques", IEEE Trans. Power Electron., vol. 14,pp. 14-22, Jan. 1999.

[74] N. Arthur, J.Penman, A. MeLean, and A. Parsons, "Induction machine condition monitoring with higher order spectra-Part I: Fundamentals and fixed frequency operation", in Proc. IEEE Ind. Electron. Soc. Annu. Conf., vol. 3, 1998, pp. 1889-1894.

[75] L. Kruger, D. Naunin, and C. Garbrecht, "Stochastic and neural models of an induction motor," Math. Comput. Simul., Vol. 46, pp. 313-324, 1998.

[76] A. J. M. Cardoso, E. S. Saraiva, M. L. S. Mateus, and A. L. Ramalho, "Onlinedetectionofairgapeccentricityin3phaseinductionmotorsby Park's vector approach", in Proc. Int. Conf. Elect. Mach. Drives, 1991, pp. 61-66.

[77] A. J. M. Cardoso and E. S. Saraiva, "Predicting the level of air-gap eccentricity in operating three-phase induction motors, by Park's vector approach", in Proc. IEEE-IAS Annu. Meeting, 1992, pp. 132-135.

[78] S. M. A. Cruz and A. J. M. Cardoso, "Stator winding fault diagnosis in threephase synchronous and asynchronous motors, by the extended Park's vector approach", in Proc. IEEE-IAS Annu. Meeting, 2000, pp. 395-401.

[79] A. J. M. Cardoso and E. S. Saraiva,
"Condition monitoring of variable speed drive systems", in Proc. Int. Conf. Power Electron. Variable-Speed Drives, 1990, pp. 519-522.

[80] A. M. S. Mendes, A. J. M. Cardoso, and E. S. Saraiva, "Voltage source inverter fault diagnosis in variable speed $A C$ drives by Park's vector approach", in Proc. Int. Conf. Power Electron. Variable-Speed Drives, 1998, pp. 538-543.

[81] A. J. M. Cardoso and A. M. S. Mendes, "Converter fault diagnosis in variable speed DC drives by Park's vector approach", in Proc. IEEE Int. Symp. Ind. Electronics, 1997, pp. 497-500.

[82] S. Nandi, R. M. Bharadwaj, and H. A. Toliyat, "Performance analysis of a three-phase induction motor under mixed eccentricity condition", IEEE Trans. Energy Convers., Vol. 17, No. 3, pp. 392-399,Sep. 2002.

[83] P. J. Tavner, B. G. Gaydon, and D. M. Ward, "Monitoringgeneratorsand large motors", Proc. Inst. Elect. Eng. B, vol. 133, no. 3, pp. 169-180, May 1986.

[84] O. V. Thorsen and M. Dalva, "Condition monitoring methods, failure identification and analysis for high voltage motors in petrochemical industry", Proc. Inst. Elect. Eng., Elect. Mach. Drives, pp. 109-113, 1997.

[85] G. B. Kliman and J. Stein, "Induction motor fault detection via passive current monitoring- A brief survey", in Proc. 44th Meeting Mechanical Failures Prevention Group, Apr. 1990, pp. 49-65. 
[86] M. E. H. Benbouzid, "A review of induction motors signature analysis as a medium for faults detection", IEEE Trans. Ind. Electron., vol. 47, no. 5, pp. 984-993, Oct. 2000.

[87] P. J. Tanver and J. Penman, "Condition Monitoring of Electrical Machines", Hertfordshire, U.K.: Research Studies Press, 1987.

[88] P. Vas, Parameter Estimation, "Condition Monitoring and Diagnosis of Electrical Machines", Oxford, U.K.: Clarendon Press, 1993.

[89] G. C. Stone, H. G. Sedding, and M. J. Costello, "Application of partial discharge testing to motor and generator stator winding maintenance", IEEE Trans.Ind. Appl., vol. 32,no. 2, pp. 459-464,Mar./Apr. 1996.

[90] Mohamed El Hachemi Benbouzid, "What Stator Current Processing-Based Technique to Use for Induction Motor Rotor Faults Diagnosis", IEEE Transactions on Energy Conversion, Vol. 18, No. 2, June, 2003.

[91] S. Williamson and K. Mirzoian, "Analysis of cage induction motors with statorwindingfaults", IEEE Trans. Power App. Syst., vol. PAS-104, no. 7, pp.1838-1842, Jul. 1985.

[92] J. L. Kohler, J. Sottile, and F. C. Trutt, "Alternatives for assessing the electrical integrity of induction motors", in Conf. Rec. IEEE IAS Annu. Meeting, 1989, vol.2, pp. 1586-1589.

[93] R. Maier, "Protection of squirrel-cage induction motors using instantaneous power and phase application", IEEE
Trans. Ind. Appl., vol. 28, no. 2, pp. 376-380, Mar./Apr. 1992.

[94] J. Penman, H. G. Sedding, B. A. Lloyd, and W. T. Fink, "Detection and location of inter-turn short circuits in the stator windings of operating motors," IEEE Trans. Energy Convers., vol. 9, no. 4, pp. 652-658, Dec. 1994.

[95] F. C. Trutt, J. Sottile, and J. L. Kohler, "Condition monitoring of induction machine stator windings using electrically excited vibrations," in Conf. Rec. IEEE IAS Annu. Meeting, 2002, vol. 4,pp.2301-2305.

[96] G. B. Kliman, W. J. Premerlani, R. A. Hoegl, and D. Hoeweler, "A new approach to on-line turn fault detection in ac motors", in Conf. Rec. IEEE IAS Annu. Meeting, 1996,vol. 1,pp. 687-693.

[97] G. Gentile, S. Meo, and A. Ometto, "Induction motor current signature analysis to diagnostics, of stator short circuits," in Proc. 4th IEEE Int. SDEMPED, Aug. 24-26, 2003, pp. 47-51.

[98] A. Stavrou, H. G. Sedding, and J. Penman, "Current monitoring for detecting inter-turn short circuits in induction motors", IEEE Trans. Energy Convers., vol. 16, no. 1, pp. 32-37, Mar. 2001.

[99] J.-H. Jung, J.-J. Lee, and B.-H. Kwon, "Online diagnosis of induction motors using MCSA", IEEE Trans. Ind. Electron., vol. 53, no. 6, pp. 1842-1852, Dec. 2006. 
[100] R. J. Lee, P. Pillay, and R. G. Harley, “ $D$, $Q$ reference frames for the simulation of induction motors", Eletric Power Syst. Res., Vol. 8, pp. 15-26, 1984/85.

[101] S. Williamson and K. Mirzoian, "Analysis of cage induction motors with stator winding faults", IEEE Trans. Power App. Syst., Vol. PAS-104, pp. 1838-1842, Jul. 1985.

[102] G. Andria, A. Dell'Aquila, L. Salvatore, and M. Savino, "Improvement in modeling and testing of induction motors", IEEE Trans. Energy Convers., Vol. EC-2, No. 2, pp. 285-293, Jun. 1987.

[103] A. Keyhani and H. Tsai, "IGSPICE simulation of induction machines with saturable inductances", IEEE Trans. Energy Convers., Vol. 4, No.1, pp. 118-125, Mar. 1989.

[104] H. M. Emara, M. E. Ammar, A. Bahgat, and H. T. Dorrah, "Stator fault estimation in induction motors using particle swarm optimization", in Proc. IEEEIEMDC, Jun. 1-4, 2003, vol. 3, pp. 1469-1475.

[105] D. Kostic-Perovic, M. Arkan, and P. Unsworth, "Induction motor fault detection by space vector angular fluctuation", in Conf. Rec. IEEE IAS Annu. Meeting, Oct. 8-12, 2000, vol. 1, pp. 388-394.

[106] N. Arthur and J. Penman, "Induction machine condition monitoring with higher order spectra", IEEE Trans. Ind. Electron., vol. 47, no. 5, pp. 1031-1041, Oct. 2000.

[107] F. C. Trutt, J. Sottile, and J. L. Kohler,
"Condition monitoring of induction motor stator windings using electrically excited vibrations", in Conf. Rec. 37th IEEE IAS Annu. Meeting, Oct. 13-18, 2002, vol. 4, pp. 2301-2305.

[108] A. I. Orille, G. M. A. Sowilam, and J. A. Valencia, "A new simulation of symmetrical three phase induction motor under transformations of Park", Comput. Ind. Eng., Vol. 37, pp. 359-362, 1999.

[109] H. A. Smolleck and B. Robertson, "Dynamic simulation of induction motor starting, using the microcomputer", Elect. Power Syst. Res., Vol. 16, pp. 227-236, 1989.

[110] S. B. Lee, R. M. Tallam, and T. G. Habetler, "A robust turn fault detection scheme for induction machines based on monitoring the sequence component impedance matrix," IEEE Trans. Power Electron., vol. 18, no. 3, pp.865-872, May 2003.

[111] R. M. Tallam, T. G. Habetler, R. G. Harley, D. J. Gritter, and B. Burton, "Neural network based stator winding turn fault detection for induction motors", in Conf. Rec. IEEE IAS Annu. Meeting, Rome, Italy, 2000, vol.1, pp.375-380.

[112] R. M. Tallam, T. G. Habetler, and R. G. Harley, "Experimenal testing of a neural network based turn fault detection scheme for induction machines under accelerated insulation failure conditions", in Proc. Int. Symp. Diagnostics Electric Mach., Power Electronics and Drives, 2003, pp. $58-62$. 
[113] Rangarajan M. Tallam, Thomas G. Habetler, and Ronald G. Harley, "Transient Model for Induction Machines With Stator Winding Turn Faults", IEEE Trans. on Ind. App., Vol. 38, No. 3, pp. 632-637, May/June 2002.

[114] Smail Bachir, Slim Tnani, Jean Claude Trigeassou, and Gérard Champenois, "Diagnosis by parameter estimation of stator and rotor faults occurring in induction machines", IEEE Trans. on Ind. Elect., Vol. 53, No. 3, pp. 963-973, June 2006.

[115] G. B. Kliman, W. J. Premerlani, R. A. Koegl, and D. Hoeweler, "A new approach to on-line turn fault detection in AC motors", in Conf. Rec. $31^{\text {st }}$ IEEE IAS Annu. Meeting, Oct. 6-10, 1996,vol. 1,pp.687-693.

[116] R. M. Tallam, T. G. Habetler, R. G. Harley, D. J. Gritter, and B. H. Burton, "Neural network based on-line stator winding turn fault detection for induction motors", in Conf. Rec. IEEE IAS Annu. Meeting, Oct. 8-12, 2000, vol. 1, pp. 375-380.

[117] R. M. Tallam, T. G. Habetler, and R. G. Harley, "Self-commissioning training algorithms for neural networks with applications to electric machine fault diagnostics", IEEE Trans. Power Electron., vol. 17, no. 6, pp. 1089-1095, Nov. 2002.

[118] L. Collamati, F. Filippetti, G. Franceschini, S. Pirani, and C. Tassoni, "Induction machine stator fault on-line diagnosis based on LabVIEW environment", in Proc. 8th Mediterr. Electrotech. Conf. MELECON, May
13-16, 1996, vol. 1, pp. 495-498.

[119] M. Arkan, D. K. Perovic, and P. Unsworth, "Online stator fault diagnosis in induction motors", Proc. Inst. Elect. Eng.-Elect. Power Appl., vol. 148, no. 6, pp. 537-547, Nov. 2001.

[120] R. M. Tallam, T. G. Habetler, and R. G. Harley, "Experimental testing of a neural-network-basedturn-fault detection scheme for induction machines under accelerated insulation failure conditions", in Proc. $4^{\text {th }}$ IEEE Int. SDEMPED, Aug.24-26, 2003, pp. 58-62.

[121] F. Briz, M. W. Degner, A. Zamarron, and J. M. Guerrero, "Online stator winding fault diagnosis in inverter-fed $A C$ machines using highfrequency signal injection," IEEE Trans. Ind. Appl., vol. 39, no. 4, pp. 1109-1117, Jul./Aug. 2003.

[122] R. R. Schoen, B. K. Lin, T. G. Habetler, J. H. Schlag, and S. Farag, " $A n$ unsupervised, on-line system for induction motor fault detection using stator current monitoring", IEEE Trans. Ind.Appl., vol. 31, no. 6, pp. 1280-1286, Nov./Dec. 1995.

[123] A. R. Munoz, "Using an autoregressive model in the detection of abnormal characteristics of squirrel cage induction motors", Elect. Power Syst. Res., Vol. 55,pp. 73-77, 2000.

[124] J. F. Martins, V. F. Pires, and A. J. Pires, "Unsupervised neural-network based algorithm for an on-line diagnosis of three-phase induction motor stator fault", IEEE Trans. Ind. Electron., vol. 
54, no. 1,pp. 259-264, Feb. 2007.

[125] N. Arthur, J.Penman, A. MeLean, and A. Parsons, "Induction machine condition monitoring with higher order spectra-Part II: Variable frequency operation and automated diagnosis", in Proc. IEEE Ind. Electron. Soc. Annu. Conf., vol. 3, 1998, pp. 1895-1900.

[126] S. M. A. Cruz and A. J. M. Cardoso, "Multiple reference frames theory: A new method for the diagnosis of stator faults in three-phase induction motors", IEEE Trans. Energy Convers., vol. 20, no. 3, pp. 611-619, Sep. 2005.

[127] J. L. Kohler, J. Sottile, and F. C. Trutt, "Alternatives for assessing the electrica lintegrity of induction motors", IEEE Trans. Ind. Appl., vol. 28, no. 5, pp. 1109-1117, Sep./Oct. 1992.

[128] G. R. Slemon, "Modeling of induction machines for electric drives", IEEE Trans. Ind. Appl., Vol. 25, No. 6, pp. 1126-1131, Nov./Dec. 1989.

[129] A. Bellini, F. Filippetti, G. Franceschini, and C. Tassoni, "Closed-loop control impact on the diagnosis of induction motors faults", IEEE Trans. Ind. Applicat., Vol. 36, No. 5, pp. 1318-1329, Sep./Oct. 2000.

[130] J. L. Kohler, J. Sottile, and F. C. Tru J. L. Kohler, J. Sottile, and F. C. Trutt, "Condition monitoring of stator windings in induction motors: part-I. Experimental investigation of the effective negative-sequence impedance detector", IEEE Trans. Ind. Appl., vol. 38, no. 5, pp. 1447-1453, Sep./Oct. 2002.
[131] J. L. Kohler, J. Sottile, and F. C. Trutt, "Condition monitoring of stator windings in induction motors: part-II. Experimental investigation of voltage mismatch detectors", IEEE Trans. Ind. Appl., vol. 38, no. 5, pp. 1454-1459, Sep./Oct. 2002.

[132] F. Zidani, M. E. H. Benbouzid, D. Diallo, and M. S. Nait-Said, "Induction motor stator faults diagnosis by a current Concordia pattern-based fuzzy decision system", IEEE Trans. Energy Convers., Vol. 18, No. 4, pp. 469-475, Dec. 2003.

[133] S. M. A. Cruz and A. J. M. Cardoso, "Diagnosis of stator inter-turn short circuits in DTC induction motor drives", IEEE Trans. Ind. Appl., vol. 40, no. 5, pp. 1349-1360, Sep./Oct. 2004.

[134] F. Filippetti, G. Franceschini, C. Tassoni, and P. Vas, "AI techniques in induction machines diagnosis including the speed ripple effect", IEEE Trans. Ind. Appl., vol. 34, no.1, pp. 98-108, Jan./Feb. 1998.

[135] F. Filippetti, A. Uncini, C. Piazza, P. Campolucci, C. Tassoni, and G. Franceschini, "Neural network architectures for fault diagnosis and parameter recognition in induction machines", in Proc. 8th Mediterr. Electrotech.Conf. (MELECON), May 13-16, 1996, vol.1, pp. 289-293.

[136] S. M. A. Cruz, A. J. M. Cardoso, and H. A. Toliyat, "Diagnosis of stator, rotor and air-gap eccentricity faults in threephase induction motors based on the multiple reference frames theory," in Conf. Rec. 38th IEEE IAS Annu. 
Meeting, Oct. 12-16, 2003, vol. 2, pp. 1340-1346.

[137] N. Arthur and J. Penman, "Inverter fed induction machine condition monitoring using the bispectrum", in Proc. IEEE Signal Processing Workshop on Higher Order Statist., 1997, pp. 67-71.

[138] A. J. M. Cardoso, S. M. A. Cruz, and D. S. B. Fonseca, "Inter-turn stator winding fault diagnosis in three-phase induction motors by Park's vector approach", IEEE Trans. Energy Conversion, vol. 14, pp. 595-598, Sept. 1999.

[139] Jose Antonino-Daviu, Selin Aviyente, E. G. Strangas, and Martin Reira-Guasp, "Scale invariant feature extraction algorithm for the automatic diagnosis of rotor asymmetries in induction motors", IEEE Trans. On Industrial Infor., Vol. 9, No. 1, pp. 100-108, Feb. 2013.

[140] F. Immovilli, C. Bianchini, A. Bellini, and R. Rubini, "Bearing fault model for induction motor with externally induced vibration”, IEEE Trans. On Ind. Elect., Vol. 60, No. 8, pp. 3408-3418, Aug. 2013.

[141] B. Boukra, A. Lebaroud, and G. Clerc, "Statistical and neural-network approaches for the classification of induction machine faults using the ambiguity plane representation", IEEE Trans. Ind. Elect., Vol. 60, No. 9, pp. 4034-4042, Sep. 2013.

[142] Bashir Mahdi Ebrahimi, A. M. Takbash, and Jawad Faiz, "Losses calculation in line-start and inverter fedinduction motors under broken bar fault”, IEEE Trans. on Inst. And Measurement, Vol. 62, No. 1, pp. 141-152, Jan. 2013.
[143] Yong-Hwa Kim, Young-Woo Youn, Don-Ha Hwang, Jong-Ho Sun, and Dong-Sik Kang, "High-resolution parameter estimation method toidentify broken rotor bar faults in induction motors", IEEE Trans. on Ind. Elect., Vol. 60, No. 9, pp. 4103-4117, Sep. 2013.

[144]A. Soualhi, G. Clerc, and H. Razik, "Detection and diagnosis of faults in induction motor using an improved artificial ant clustering technique”, IEEE Trans. on Ind. Elect., Vol. 60, No. 9, pp. 4053-4062, Sept. 2013.

[145] M. Ben Khader Bouzid, and G. Champenois, "New expressions of symmetrical components of theinduction motor under stator faults", IEEE Trans. on Ind. Elect., Vol. 60, No. 9, pp. 4093-4102, Sep. 2013.

[146] J. Kim, I. Yang, D. Kim, M. Hamadache, and D. Lee, "Bearing fault effect on induction motor stator current modeling based on torque variations", $12^{\text {th }}$ National Conf. on CAS, Korea, pp. 814-818, Oct. 2012.

[147] G. M. Joksimovi', Jakša Riger, Thomas M. Wolbank, Nedjeljko Peri'c, and Mario Vašak, "Stator-current spectrum signature of healthy cage rotor induction machines", IEEE Trans. on Ind. Elect., Vol. 60, No. 9, pp. 4025-4033, Sep. 2013.

[148] B. Xu, L. Sun, and G. Xu, "Improvement of the hilbert method via esprit for detecting rotor fault in induction motors at low slip", IEEE Trans. on Energy Conversion, Vol. 28, No. 1, pp. 225-233, Mar. 2013. 
[149] K. N. Gyftakis, D. V. Spyropoulos, Joya C. kappatou and E. D. Mitronikas, " $A$ novel approach for broken bar fault diagnosisin induction motors through torque monitoring", IEEE Trans. on Energy Conversion, Vol. 28, No. 2, pp. 267-277, Jun. 2013.

[150] K. N. Gyftakis and Joya C. Kappatou, “ $A$ novel and effective method of static eccentricity diagnosis in three-phase psh induction motors", IEEE Trans. on Energy Conversion, Vol. 28, No. 2, pp. 225-233, Jun. 2013.

[151] M. Ahmadi, J. Posthan, M. Posthan, "Static eccentricity fault detection in induction motors using wavelet packet decomposition and gyration radius", 978-1-4673-2821-0/12,2013.

[152] J. Seshadrinath, bhim singh, and B. K. Panigrahi, "Investigation of vibration signatures for multiple fault diagnosis in variable frequency drives using complex wavelets", accepted for publication, 2013.

[153] S. S. Rafaat, H. Abu-Rub, M. S. Saad, E. M. Aboul-Zahab, and A. Iqbal, "Annbased for detection, diagnosis the bearing fault for three phase induction motors using current signal", 978-14673-4569-9/13, IEEE 2013.

[154] M. Dlamini, P. S. Barendse, A. Khan, "Autonomous detection of inter-turn stator faults in induction motors", 9781-4673-4569-9/13, IEEE, 2013.

[155] S. Lee, J. hong, S. Bin Lee, E. Wiedenbrug, M. Teska, and H. Kim, "Evaluation of the influence of rotor axial air ductson condition monitoring of induction motors", accepted for publication, 2013.

[156] S. S. Rafaat, H. Abu-Rub, M. S. Saad, E. M. Aboul-Zahab, and A. Iqbal, "Fault tolerance of stator turn fault for three phase induction motors star-connected using artificial neural network", 978-14673-4355-8/13, IEEE, 2013.

[157] B. Amel, S. Sami, Y. laatra, and D. Nourreddine, "Classification and diagnosis of broken rotor bar faults in induction motor using spectral analysis and SVM", $8^{\text {th }}$ International Conf. and Exhibition on Ecological Veh. \& Ren. Ener. (EVER), 978-1-4673-5271-0/13, IEEE, 2013.

[158] Vicente Climente-Alarcon, José Antonino-Daviu, Francisco VedreñoSantos, and Rubén Puche-Panadero, "Vibration transient detection of broken rotor bars by PHS sidebands", accepted for publication, 2013.

[159] Y. Gritli, A. O. Di Tommaso, R. Miceli, C. Rossi, and F. Filipetti, "Quantitative rotor broken bar evaluation in double squirrel cage induction machines under dynamic operating conditions", $8^{\text {th }}$ International Conf. and Exhibition on Ecological Veh. \& Ren. Ener. (EVER), 978-1-4673-5271-0/13, IEEE, 2013.

[160] S. Bikash Chaudhary, M. Sengupta, and K. Mukherjee, "Experimental study of induction motor misalignment and its online detection through data fusion", IET Electric Power Applications, Vol. 7, No. 1, pp. 58 - 67, Sept. 2012.

[161] Piotr Kolodziejek, "Noninvasive method for rotor fault diagnosis in the 
inverter fed induction motor drive”, $8^{\text {th }}$ International Conf. and Exhibition on Ecological Veh. \& Ren. Ener. (EVER), 978-1-4673-5271-0/13, IEEE, 2013.

[162] J. hong, D. hyun, S. Bin Lee, and C. Kral. "Offline monitoring of airgap eccentricity for inverter-fed induction motors based on the differential inductance", accepted for publication, 2013.

[163] Fernanda M. C. Santos, Ivan N. da Silva, and Marcele Suetake, "Neural network classifier for faults detection in induction motors", 978-1-4673-52857/13, IEEE, 2013.

[164] Rastko Fišer, Klemen Drobnič, Henrik Lavrič, Mitja Nemec, Vanja Ambrožič, and Danilo Makuc, "Induction motor parameters in case of rotor electrical asymmetry”, 978-1-4673-5658-9/13, IEEE, 2013.

[165] M. A. Armenta-Loredo and O. G. IbarraManzano, "Application of higher order spectral analysis for faults detection in induction motors", 978-1-4673-61552/13, IEEE, 2013.

[166] Fernando Salazar-Villanueva and Oscar G. Ibara-Manzano. "Spectral analysis for identifying faults in induction motors by means of sound", 978-1-4673-61552/13, IEEE, 2013.

[167] T. Kato, K. Inoue, K. Yoshida, and T. Itokava, "Diagnosis of multi-turn faults of induction motorby direct detection of asymmetry admittance component", 978-1-4673-1792-4/13, IEEE, 2013.

[168] M. S. Rama Krishna and Ravi Kiran S., "Fault diagnosis olinduction motor using motorcurrent signature analysis", International Conf. on Circuits, Powerand Computing Technologies, 978-1-4673-4922-2/13, IEEE, 2013.

[169] Subhash M., Nagarajan S. and Rama Reddy S., "Detection and analysis 0/ eccentricity in three phase squirrel cage induction motor using FEM", International Conf. on Circuits, Powerand Computing Technologies, 978-1-4673-4922-2/13, IEEE, 2013.

[170] A. A. Silva, Ali M. Bazzi, and Shalabh Gupta, "Fault diagnosis in electric drives using machine learning approaches", 978-1-4673-4974-1/13, IEEE, 2013.

[171] Damian S., Vilchis-Rodriguez, Sinisa Djurovic, and Alexander C. Smith, "Wound rotor induction generator bearing fault modeling and detection using stator current analysis", IET Renew. Power Gener., Vol. 7, Iss. 4, pp. 330-340, Feb. 2013.

[172] A. Q. Flores, A. J. Marques Cardoso, J. B. Carvalho, "Gearbox fault detection by wavelet and spectrum analysis of the induction motor power", 978-1-46734974-1/13, IEEE, 2013

[173] Mikhail Tsypkin, "Induction motor condition monitoring: vibration analysis technique - A twice line frequency component as a diagnostic tool”, 978-1-4673-4974-1/13, IEEE, 2013

[174] Muhammad Irfan, Nordin Saad, Rosdiazli Ibrahim, Vijanth S. Asirvadam, "Development of an 
intelligent condition monitoring system for ac induction motors using PLC", Buis. Engg. And Ind. App. Colloquium, 978-1-4673-5968-9/13, IEEE, 2013.

[175] Yuan Gui-li, QIN Shi-wei, and GAN Mi, "Motor fault diagnosis of RBF neural network based on immune genetic algorithm", 25 $5^{\text {th }}$ Chinese Control and Decision Conference, 978-1-46735534-6/13, IEEE, 2013.

[176] Wei Hu, Gui Liu, Li Fu, Hongmei Zhang, "Research of motor fault diagnosis based on pso algorithm", $25^{\text {th }}$ Chinese Control and Decision Conference,978-1-4673-5534-6/13, pp. 1060-1065, IEEE, 2013.

[177] Mohamed Salah, Khmais Bacha, Abdelkader Chaari, "Stator current analysis of a squirrel cage motor running under mechanical unbalance condition", $10^{\text {th }}$ International MultiConference on systems, Signals and Devices, 978-1-4673-5534-6/13, IEEE, 2013.

[178] Houda Chouiref, Boumedyen Boussaid, M. Naceur Abdelkrim, Christophe Aubrun, "Nonlinear fault tolerant control based parameter estimation diagnosis: application to induction motors", $10^{\text {th }}$ International MultiConference on systems, Signals and Devices, 978-1-4673-6457-7/13, IEEE, 2013. An intelligent diagnostic system for the conditionmonitoring of ac motors

[179] Muhammad Irfan, Nordin Saad, Rosdiazli Ibrahim, Vijanth S. Asirvadam, "An intelligent diagnostic system for the condition monitoring of ac motors", $8^{\text {th }}$ Conference on Ind. Elect.
And App., 978-1-4673-6322-8/13, pp. 1248-1253, IEEE, 2013.

[180] Carlos Pezzani, Pablo Donolo, Guillermo Bossio, Marcos Donolo, Armando Guzmán, and Stanley E. Zocholl, "Detecting broken rotor bars with zero setting protection", accepted for publication, IEEE, 2013. 